\title{
УЧЕТ РЕЗУЛЬТАТОВ ДЕЯТЕЛЬНОСТИ СЛУЖБЫ ВНУТРЕННЕГО АУДИТА ДЛЯ ПРОВЕДЕНИЯ ОПЕРАЦИОННОГО DUE DILIGENCE
}

\author{
(c) 2021 Феофилова Татьяна Юрьевна \\ доцент, Высшая инженерно-экономическая школа \\ Санкт-Петербургский политехнический университет Петра Великого, Россия, Санкт-Петербург \\ E-mail: feofilova_tyu@spbstu.ru
}

(c) 2021 Заиченко Демид Викторович

студент, Высшая инженерно-экономическая школа

Санкт-Петербургский политехнический университет Петра Великого, Россия, Санкт-Петербург

E-mail: zaichenko.dv@edu.spbstu.ru

(C) 2021 Дуболазова Юлия Андреевна

доцент, Высшая инженерно-экономическая школа

Санкт-Петербургский политехнический университет Петра Великого, Россия, Санкт-Петербург

E-mail: dubolazova_yua@spbstu.ru

В статье приведен обзор истории развития Due Diligence и его актуализация в российской экономике. Выделены сферы применения процедуры Due Diligence и её основные виды. Кроме того, показана и обоснована возможная область использования результатов службы внутреннего аудита в целях операционного вида Due Diligence. Обозначены основные предпосылки для службы внутреннего аудита, которые бы позволяли использовать её результаты в целях Due Diligence. В завершении приведен программный продукт, оптимизирующий процедуру Due Diligence, и обозначены направления дальнейших исследований.

Ключевые слова: процедура Due Diligence, сферы применения Duе Diligence, экономическая безопасность компании, служба внутреннего аудита, предынвестиционное исследование проектов, управление рисками.

Введение. В условиях современной рецессии мировой экономики и российской в частности, необходимость в поиске путей развития и масштабирования существующих бизнесов только возросла. В этой связи особую роль приобретает требование повышения прозрачности отечественного бизнеса для потенциальных партнеров, чему во многом может поспособствовать проведение участниками российского рынка независимой, профессиональной и комплексной проверки целевого экономического субъекта, которая позволит значительно снизить риски, сопутствующие заключению сделок по слиянию или поглощению. Одним из самых надежных современных инструментов такой проверки бизнеса на «чистоту» является процедура Due Diligence, сфера приложения которой рассматривается в настоящем исследовании.

Цель исследования заключается в определении возможностей использования результатов службы внутреннего аудита в процессе проведения операционного Due Diligence для

заключения сделки слияния и поглощения.

Методы. В ходе проведения настоящего исследования применялись методы сравнительного анализа, теоретического моделирования, метод аналогий, а также интеграции существующих подходов к применению процедуры Due Diligence.

Литературный обзор. На российском рынке процедура Due Diligence начала внедряться в практику с момента вхождения на него международных консалтинговых фирм и постепенно приобрела популярность в бизнес-сообществе, чему во многом способствовали экономические реформы в области бухгалтерского учета и налогового законодательства [1].

B научной литературе упоминание Due Diligence встречается крайне редко. Многие авторы приравнивают инвестиционный аудит к процедуре Due Diligence, хотя она не сводится только к нему. Рост популярности внедрения Due Diligence начался примерно с 2015 года и во многом связан с работами таких авторов как 
Григоренко О.В. и Садовничьей И.О. [2], Гузова Ю.Н. и Савенковой Н.Д. [3], Корсаковой М.Н. и Музолева И.В [6], Кузьмина Е.В. и Кудряшовой А.А. [7], Кутер М. И. и Антоновой Н.А. [8], Романовского М. В. [10], Стяжкиной И. В. [11] и др.

Результаты исследования. В России процедура Due Diligence получила наибольшее pacпространение при совершении сделок в области слияния и поглощения компаний (M\&A).

Определение Due Diligence (англ.) в переводе на русский язык означает «разумная предосторожность» или «должная осмотрительность». Считается, что этот термин был введен в 30-е годы XX века в Соединенных Штатах Америки. Первоначально речь шла о порядке раскрытия брокером инвестору информации о компании, акции которой были проданы на открытом фондовом рынке [1].

В последнее время это понятие приобрело довольно широкое значение. Сегодня Due Diligence - это комплексное предынвестиционное исследование, проводимое либо самим инвестором, либо командой консультантов с целью оценки различных рисков, связанных с инвестированием капитала. Как правило, она осуществляется при принятии решения о покупке доли в бизнесе или бизнес-проекте в целом [2]. Иногда Due Diligence определяется как надлежащее исследование, проводимое заинтересованными сторонами при подготовке документов по сделке с целью формирования доверительной основы относительно истинности и полноты положений документов и содержащихся в них фактов. В некоторых случаях под этим термином понимается сбор и анализ информации о потенциальных или существующих клиентах и партнерах с целью оценки их финансового состояния и надежности.

Основная цель Due Diligence заключается в проведении анализа, позволяющего хозяйствующим субъектам исключить или в значительной степени минимизировать возможные негативные последствия (возможные угрозы) предполагаемой сделки, а также оптимизация бизнес-процессов в последующей деятельности компании.

В компаниях, основным видом деятельности которых является оказание услуг подобного рода, необходимость ограничения срока проверки объясняется тем, что клиент не должен потерять интерес к услугам компании за то время, пока менеджер выясняет ее благонадежность [8].
На практике возможны следующие пути приобретения существующего бизнеса, которыми может воспользоваться инвестор [3]:

1) покупка акций (долей в уставном капитале) компании;

2) покупка части активов предприятия;

3) приобретение предприятия как самостоятельного имущественного комплекса (со всеми его активами и обязательствами);

4) реорганизация юридического лица в форме слияния либо присоединения.

Наиболее часто к услугам специалистов по проведению Due Diligence инвестор обращается в 3-м и 4-м случае, так как зачастую инвестор не располагает достаточной квалификацией и временем для получения достоверного, объективного и полного отчета о состоянии дел в привлекательной компании.

Исходя из мировой практики можно выделить следующие виды проведения процедуры Due Diligence [7]:

- финансовый;

- правовой (юридический);

- налоговый;

- операционный (управленческий);

- коммерческий;

- маркетинговый

Общий операционный или организационноуправленческий Due Diligence - специальное исследование системы управления предприятием в целом и/или его отдельных подсистем для оценки качества управления, наличия рисков, эффективности производства резервов, потенциала развития [12]. Оно также включает в себя проверку наличия и качества следующих элементов системы управления в компании: стратегия, оперативная деятельность и производство, персонал, внешние связи и коммуникации, закупки, сбыт, а также система внутреннего контроля.

Как можем заметить, проверка наличия и качества таких элементов управления требует предоставления внутренней информацией от руководителей соответствующих бизнеспроцессов, что в условиях ограниченности сроков проведения Due Diligence не всегда является приемлемым [4]. В связи с этим, решением данной проблемы может стать учет результатов деятельности подразделения внутреннего аудита (ПВА) рассматриваемой компании.

Вкратце деятельность ПВА сводится к предоставлению собственникам компании независи- 
мых и объективных гарантий в области исследования:

1) эффективности системы корпоративного управления (СКУ);

2) эффективности системы управления рисками (СУР);

3) эффективности системы внутреннего контроля (СВК).

Результаты исследований и оценок ПВА во всех трех областях являются наиболее релевантными для целей операционного Due Diligence. Однако прежде чем учитывать данные результаты для приобщения к итогам операционного Due Diligence, необходимо удостовериться в независимости, а также в квалификации ПВА рассматриваемой компании. Для этого консультантам, проводящим операционный Due Diligence, целесообразно оценить ПВА по следующим критериям [9]:

- наличие функциональной подотчетности Совету Директоров или собственникам компании (утверждение Положения о ПВА, план деятельности и бюджет ПВА);

- наличия ресурсов и доступ к информации, предоставляемых высшим исполнительным руководством для выполнения заданий по предоставлению гарантий ПВА;

- наличие профессиональной квалификации (например, Certified Internal Auditor - CIA или высшего экономического образования), а также достаточного опыта работы сотрудников ПВА.

При соответствии ПВА, рассматриваемой компании обозначенным критериям команда консультантов, проводящих процедуру операционного Due Diligence, будет иметь разумную уверенность в качестве оценок ПВА и возможность учета их для целей Due Diligence. При этом не все области деятельность компании - цели можно оценить на основе результатов оценок ПВА, ряд из них должны быть проанализированы при проведении Due Diligence. Такие области проверки представлены в таблице 1 .

Исходя из таблицы 1 , команде консультантов необходимо применять риск-ориентированный подход в ходе операционного Due Diligence и сосредоточиться на проверке вопросов с высоким уровнем риска для целей слияния. Для получения информации от ПВА предварительно следует согласовать между Покупателем, Продавцом и командой Due Diligence список необходимых документов и сроки их предоставления. Договоренности следует обозначить в специальном разделе Соглашения о намерениях между Покупателем и Продавцом.

После заключения Соглашения о намерениях руководителям команды Due Diligence и ПВА необходимо наладить взаимодействие по обмену установленными документами и комментариями по их анализу. Следует отметить, что все документы, включая отчеты ПВА, рекомендуется хранить в виртуальной «комнате данных» (virtual data room). Такие «комнаты» позволяют всем стейкхолдерам сделки иметь беспрепятственный доступ к нужным документам и оперативно отслеживать изменения в ходе процесса заключения сделки.

После анализа всех предоставленных доку-

Таблица 1. Учет результатов проверок СВА для операционного Due Diligence

\begin{tabular}{|c|l|l|}
\hline № & \multicolumn{1}{|c|}{ Область проверки } & \multicolumn{1}{|c|}{ Возможность учета результатов } \\
\hline 1 & $\begin{array}{l}\text { История и перспективы развития рассматриваемой } \\
\text { компании }\end{array}$ & $\begin{array}{l}\text { Самостоятельный анализ команды } \\
\text { консультантов }\end{array}$ \\
\hline 2 & $\begin{array}{l}\text { Оценка релевантности текущей организационно- } \\
\text { правовой формы компании }\end{array}$ & Учет результатов ПВА \\
\hline 3 & $\begin{array}{l}\text { Эффективность организационной структуры и уровень } \\
\text { корпоративного управления }\end{array}$ & Учет результатов ПВА \\
\hline 4 & Квалификация менеджмента и сотрудников компании & Учет результатов ПВА \\
\hline 5 & Внешняя среда функционирования компании & $\begin{array}{l}\text { Самостоятельный анализ команды } \\
\text { консультантов }\end{array}$ \\
\hline 6 & $\begin{array}{l}\text { Принципы управления имуществом, кадастровой стои- } \\
\text { мостью и финансами компании }\end{array}$ & $\begin{array}{l}\text { Самостоятельный анализ команды } \\
\text { консультантов }\end{array}$ \\
\hline 7 & Система внутреннего контроля компании & $\begin{array}{l}\text { Учет результатов ПВА с выборочным } \\
\text { тестированием }\end{array}$ \\
\hline 8 & $\begin{array}{l}\text { Эффективность производственных и инжиниринговых } \\
\text { процессов, инвестиционной программы }\end{array}$ & Учет результатов ПВА \\
\hline
\end{tabular}

Источник: составлено авторами статьи 
ментов команда Due Diligence формирует предварительный итоговый отчет и предоставляет его для ознакомления и согласования всем сторонам сделки, включая ПВА. Если возникают разногласия с выводами команды Due Diligence, то эти выводы дополнительно обсуждаются и в случае необходимости проводится повторная проверка проблемных вопросов. Затем снова команда Due Diligence предоставляет доработанный отчет всем сторонам сделки. В случае единогласного одобрения команда Due Diligence формирует окончательный отчет и отправляет его сторонам сделки на подпись.

Таким образом, использование результатов оценок ПВА целесообразно оправдано при проведении процедуры Due Diligence, способствует сокращению сроков и может повысит её качество.

Несмотря на аргументированность вывода об использовании результатов оценок ПВА компании-цели при сделках слияния, методическое обеспечение недостаточно разработано, что требует его развития и дальнейшего исследования.

\section{Библиографический список}

1. Галлямова Д. А. История развития и становления Due Diligence за рубежом и в России // Вектор экономики. 2020. № 8 (50). С. 17.

2. Григоренко О.В., Садовничая И. О. Специальная процедура комплексной проверки - Дью Дилидженс: актуальные вопросы теории и практики // Интернет-журнал «НАУКОВЕДЕНИЕ» Том 9, № 4 (2017)

3. Гузов Ю.Н., Савенкова Н.Д. Дью Дилидженс: вопросы теории и практики // Аудиторские ведомости. 2015. № 7. C. 56-69.

4. Изварина Н.Ю., Руденко К.А., Падалка О. И. Использование внутреннего аудита в повышении безопасности бизнес-модели // Экономика и бизнес: теория и практика. 2020. № 5-3.

5. Коломиец-Людвиг Е. П. Применение некоторых инновационных технологий при осуществлении сделок по слияниям и поглощениям // Наука. Общество. Государство. 2013. № 4

6. Корсаков М.Н., Музолев И. В. Due Diligence: понятие, проблемы и перспективы развития в России // Вестник ТИУиЭ. 2018. № 2 (28).

7. Кузьмин Е.В., Кудряшов А.А. Перспективы использования метода Due Diligence в российских компаниях // Актуальные проблемы гуманитарных и естественных наук. 2016. № 4-2.

8. Кутер М.И., АнтоноваН.А.Концепция процедуры Дью-Дилидженс как современной аудиторскоконсалтинговой услуги // Учет. Анализ. Аудит. 2016. № 6. С. 51-65.

9. Рау Э.И. Становление службы внутреннего аудита как инструмента развития и безопасности бизнеса в практике российских компаний // Российское предпринимательство. 2018. № 6.

10. Романовский М.В., Стяжкина И. В. Применение процедуры Дью Дилидженс в современной России // Финансовые исследования. 2016. № 4 (53).

11. Стяжкина И. В. Особенности проведения процедуры Дью Дилидженс в России // Известия СПбГЭУ. 2016.

12. Rajiv Jaitly. Practical Operational Due Diligence on Hedge Funds: Processes, Procedures and Case Studies / Wiley; 1st Edition (March 21, 2016) ISBN: 978-1-119-01875-9 